\title{
FIRE, FLOOD AND ICE: SEARCH AND RESCUE MISSIONS OF THE SOUTH AFRICAN AIR FORCE
}

Dick Lord

Covos Books: Johannesburg, 1998

215 pages

illustrated, maps

ISBN 0620229012

R149-95

Between the end of 1999 and the early months of the year 2000, the south western parts of South Africa (SA) were subjected to raging infernos that saw a lot of commercial wine farms as well as tourist spots almost irreparably ravaged. With volunteers and rescue personnel still gasping for fresh breath another disaster, in the form of torrential rains, struck the impoverished country of Mozambique and the north western parts of SA. The attendant floods did not only cripple agriculture but also drowned people and livestock alike. With them, also came the first "treebirth" in this new millennium (if not in the history of mankind). In both catastrophes, the men and women of the South African Air Force (SAAF), as well as thousands of other volunteers, worked tirelessly and unselfishly in efforts to save endangered lives and property and to bring a sense of normality in otherwise tragic circumstances.

Similar acts of sacrifice and courage in the face of humanitarian disaster are the focus of Dick Lord's book Fire, Flood and Ice. Spanning thirty-eight chapters the book takes the reader through extremes of all sorts. From the "die hard" scenes of the so-called Bush War to the adventures of mountain climbing and skiing; from the icy Antarctic to the scotching heat of Namibia and Angola; from persistent airport officials who desperately try to enforce customs regulations to laws broken by aviators simply because not to could have results too ghastly to contemplate; from highly publicised and recognised rescue efforts to obscure ones that few have ever heard of; from the joy of another life saved to the sadness of one that could not be saved. This book is, however, not about extremes. Rather, it is about the selfless sacrifices made by those who defy survival instincts to ensure that fellow beings survive. The task of writing about such deeds could only be successfully accomplished by one who has not only flown aircraft before but has also benefited from the aforesaid sacrifices - in this regard, Dick Lord is not wanting.

Each of the book's chapters is made of two to three, inherently unrelated, events that are grouped together chiefly because one/two of the rescue crew members were involved. As such, there is often a time as well as conceptual hiatus within a chapter - making the "progressive" review on a chapter by chapter basis a difficult endeavor. Instead of attempting such a review, attention will be paid to those features/characteristics that not only make the book unique but also worth reading. The first of these is the inclusion of biographies at the end of each chapter. (In Dick Lord's words) This personalisation of events enables relatives and colleagues to say that's my son or my father or friend. In terms of language the book freely mixes English, Afrikaans and Zulu - and this gives it truly South African flavour. The author also does well not to assume that the "audience" is au fait with aviation jargon, hence 
his inclusion of a glossary of terms. Lord goes further to explain a few other technicalities like the date time group used in the military as well as the measurement of height and distance. All these features, as well as Lord's ability to blend tragedy with humour, lend the book originality that is often missing in similar works.

The books central character, Murphy, turns out to be the master of disguise who pitches up in the form of rain, inaccessible gorges and seagulls bent on flying "in formation" with rescue helicopters. Murphy is, however, unfortunate as his unwelcomed appearances often run into determined and well trained rescue personnel, durable equipment and a bit of divine luck. If one does not read the book simply because it is interesting, then one should read it only because of the sheer human ingenuity that Lord so eloquently conveys.

Despite Lord's blatantly unapologetic renditions of the SAAF's involvement in the destabilisation of Frontline states - the book represents the sincere gratitude of the millions who have been and continue to be assisted by the SAAF in times of need.

Lindelwa Simphiwe Mnyandu, Defence Analyst, Defence Research Centre. 